\title{
Prions ou pas prions: souris transgéniques et vaches folles
}

médecine/sciences a fait le point sur les prions dans deux nouvelles récentes; ces protéines mystérieuses qui s'accumulent dans le système nerveux au cours d'encéphalites humaines dégénératives mais transmissibles (maladie de Creutzfeldt-Jakob, kuru) et animales (tremblante du mouton et de la chèvre ou scrapie). L'équipe de Prusiner (San Francisco, CA, USA), qui attribue aux prions eux-mêmes le pouvoir infectieux, pense que c'est la séquence de la protéine prion $(\operatorname{PrP})$ qui gouverne le mode de transmis-, sion de la maladie, notion qui rejoint celle des barrières d'espèce, le passage de la tremblante étant souvent impossible d'une espèce à une autre [1, 2]. Pour tester cette hypothèse, des gènes de hamster syrien $(\mathrm{HaPrP})$ ont été injectés à des embryons de souris pour produire des souris transgéniques [3]. On a ensuite étudié sur ces souris la sensibilité aux prions de hamster et de souris, comparée à celle des souris normales. On a obtenu trois souris possédant dans leur génome les fragments caractéristiques du gène $\mathrm{HaPrP}$. Dans le cerveau de ces animaux, le messager est présent ainsi que la protéine prion de hamster, qui diffère immunologiquement de celle de souris. Le résultat fondamental est que, si on inocule à ces animaux des prions de hamster, la période d'incubation avant maladie clinique est fortement raccourcie chez les transgéniques et eux seuls. De plus, la barrière interspécifique a été levée. Pour les auteurs [3], la spécificité d'espèce tient à la différence des séquences (14 acides aminés diffèrent entre souris et hamster), et des travaux ultérieurs devront établir quelles sont celles qui sont importantes.

A la limite, que pourrait donner la $\mathrm{m} / \mathrm{s} n^{\circ} 3$ vol. 6 , mars 90 mutation d'un seul acide aminé ? on a déjà des éléments de réponse, puisque dans une maladie génétique voisine mais différente de la maladie de Creutzfeldt-Jakob, une mutation ponctuelle (Pro $\rightarrow$ Leu) a été trouvée dans plusieurs familles, comme nous l'avons relaté il y a un an. Depuis lors, on a décrit une autre mutation ponctuelle dans la protéine prion de sujets atteints de Creutzfeldt-Jakob (m/s $n^{\circ} 1$, vol. 6, p. 77); ainsi qu'une insertion de $0,15 \mathrm{~kb}$ dans la partie codante du gène dans des cas aussi bien de Creutzfeldt-Jakob que de GerstmannSträusster [4, 5]

Il reste cependant difficile de démêler l'intrication de facteurs génétiques et infectieux dans ces maladies, et surtout de savoir s'il existe des acides nucléiques infectants qui pourraient différer entre plusieurs souches. Les vues de Prusiner, en effet, sont loin de faire l'unanimité. Beaucoup pensent qu'il existe des souches distinctes de tremblante, dues à la présence de matériels génétiques différents.

La controverse théorique se double d'enjeux économiques et médicaux considérables, touchant précisément les barrières d'espèces $[6,7]$. Elle a pour point de départ l'épidémie d'encéphalite spongiforme ou " maladie des vaches folles ", dont ont été victimes - en trois ans environ 10000 bovins en Grande-Bretagne. L'opinion prévaut que c'est la consommation par ces bovins d'abats provenant de moutons atteints de tremblante qui en est responsable. Il n'y aurait donc, dans ce cas, pas de barrière entre bovins et ovins. Mais la crainte a été exprimée qu'il existerait des risques d'apparition de maladie de Creutzfeldt-Jakob chez des humains à la suite de consommation de viande de bœuf contaminée. Cela est certes peu probable, puisque la tremblante du mouton, endémique depuis des siècles, ne paraît pas contagieuse pour l'homme. En tous cas, cette crainte a suffi pour qu'en Grande-Bretagne ori ait mis sur pied une enquête, dotée de fonds importants, destinée à détecter une éventuelle augmentation inhabituelle de la fréquence de la maladie de Creutzfeldt-Jakob.

Cette épizootie, que l'on pourrait enrayer en cessant de donner des abats de mouton aux bovins, est un effet pervers imprévu d'un procédé souvent recommandé en écologie, le " recyclage" des déchets; elle ne devrait pas être utilisée pour condamner le principe mais devrait inciter à surveiller de près les conséquences de l'emploi de méthodes nouvelles.

J.C.D.

1. Westaway D, Goodman PA, Mirenda CA et al. Distinct prion protein in short and long scrapie incubation period mice. Cell 1987 ; 51 651-62.

2. Westaway D, Carlson GA, Prusiner SB Unraveling prion diseases through molecular genetics. Trends Neurosci 1989 ; 12 : 221-7. 3. Scott M, Foster D, Mirenda CA, et al Transgenic mice expressing hamster prion protein produce species-specific scrapie infectivity and amyloid plaques. Cell $1989 ; 69$ : 847-57. 4. Owen F, Poulter M, Lof thouse R. Inser tion in prion protein gene in familial Creutzfeldt-Jakob disease. Lancet 1989; 1 61-2.

5. Collinge J, Harding AG, Owen F. Diagnosis of Gerstmann-Sträussler syndrome in familial dementia with prion protein gene analy sis. Lancet 1989 ; ii : 15-6.

6. Editorial. Plague upon plague. Nature 1990 343: 193-4.

7. Aldhous P. BSE causing public alarm Nature 1990 ; 343 : 196.

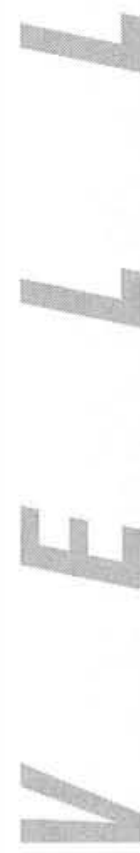

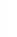

. 